\title{
GEOLISTRIK KONFIGURASI WENNER UNTUK PENDUGAAN AIR TANAH DI PERUMAHAN GRAND PURI BUNGA NIRWANA JEMBER
}

\author{
Eri Kusworowati ${ }^{1)}$, Gusfan Halik ${ }^{2}$, Wiwik Yunarni $\mathbf{W}^{3)}$ \\ Jurusan Teknik Sipil, Fakultas Teknik, Universitas Jember, Jember \\ Email:erikusworo11@gmail.com ${ }^{1)}$,gusfan.teknik@unej.ac.id ${ }^{2)}$,wiwik.teknik@unej.ac.id ${ }^{3)}$
}

DOI: http://dx.doi.org/10.29103/tj.v10i1.245

(Received: July 2019 / Revised: August 2019 / Accepted: January 2020)

\begin{abstract}
Abstrak
Air merupakan kebutuhan pokok bagi manusia. Air tanah salah satu alternatif sebagai sumber air bersih. Penelitian ini bertujuan untuk menyelidiki potensi air tanah di Perumahan Grand Puri Bunga Nirwana, Jember. Penelitian menggunakan metode geolistrik dengan konfigurasi wenner. Panjang lintasan akuisisi data 410 meter. Jarak spasi antar elektroda (a) yang digunakan yaitu $5 \mathrm{~m}, 10 \mathrm{~m}$ dan $15 \mathrm{~m}$. Pengulangan data (n) dilakukan sebanyak 6 kali pada masing-masing jarak spasi antar elektroda. Inversi model menggunakan software Res2Dinv. Hasil inversi berupa citra penampang lapisan bawah tanah. Nilai resistivitas yang diperoleh 0,55-371 $\Omega \mathrm{m}$. Potensi air tanah berada di kedalaman 38-51,8 m. Akuisisi data terletak pada koordinat 8¹0,29'40" S dan $113^{\circ} 44^{\prime} 7,20^{\prime \prime}$ E. Lapisan akuifer tergolong akuifer produktif sedang. Debit akuifer diprediksi kurang dari 5 liter/detik.
\end{abstract}

Kata kunci: geolistrik, wenner, resistivitas, akuifer

\begin{abstract}
Water is a primary human need. Groundwater is an alternative source of fresh water. This research aims to investigate the potential of groundwater at the Grand Puri Bunga Nirwana Housing, Jember. The study used the geoelectric method with a Wenner configuration. The acquisition data length is 410 meters. The distance between the electrodes used $5 \mathrm{~m}, 10 \mathrm{~m}$ and $15 \mathrm{~m}$. Repeating data 6 times at each spacing between electrodes. Inversion of the model using Res2Dinv software. The inversion results in the form of a cross-sectional image of the underground layer. The resistivity value obtained $0.55-371 \Omega \mathrm{m}$. The depthof groundwater potential is $38-51.8 \mathrm{~m}$. Coordinates of data acquisition are $8^{\circ} 10.29^{\prime} 40$ 'S and $113^{\circ} 44^{\prime} 7.20^{\prime}$ 'E. Aquifer layers are classified as medium productive aquifers. The predicted discharge of aquifer is less than 5 liters/second.
\end{abstract}

Keywords: geoelectric, wenner, resistivity, aquifer

\section{Latar Belakang}

Pertumbuhan jumlah penduduk meningkatkan kebutuhan hunian. Perumahan Grand Puri Bunga Nirwana Jember merupakan salah satu penyedia kebutuhan hunian. Masyarakat sekitar umumnya menggunakan sumur dangkal sebagai sumber mata air. Adanya pembangunan perumahan tentu akan meningkatkan kebutuhan air karena bertambahnya jumlah penduduk. Air tanah bisa menjadi salahsatu alternatif untuk menghadapi peningkatan kebutuhan air, sehingga diperlukan sebuah penelitian untuk menduga keberadaan air tanah. 
Potensi ketersediaan air tanah yang tersimpan pada akuifer di bawah permukaan bumi di Kabupaten Jember belum diketahui dengan baik, karena penyebaran dan posisi serta dimensi akuifer serta hubungan antar akuifer belum diketahui dengan baik (Priyono dan Rizal, 2013). Tujuan penelitian ini adalah menyelidiki potensi air tanah di Perumahan Grand Puri Bunga Nirwana Jember.

Menurut Bisri (2003) ada beberapa metode pendugaan, diantaranya: metode gravitasi, metode geologi, metode geolistrik, metode seismik, dan metode magnit. Dari berbagai metode, salah satu metode yang baik digunakan yaitu metode geolistrik tahanan jenis (Bakri dkk, 2015). Metode geolistrik telah terbukti kehandalannya untuk menentukan lapisan akuifer di bawah permukaan bumi. Pendugaan geolistrik ini didasarkan pada kenyataan bahwa material yang berbeda akan mempunyai tahanan jenis yang berbeda apabila dialiri arus listrik (Halik dan Widodo, 2008). Metode geolistrik merupakan metode yang banyak sekali digunakan dan hasilnya cukup baik yaitu untukmemperoleh gambaran mengenai lapisan tanah dibawahpermukaan dan kemungkinan terdapatnya air tanah (Wijaya, 2015). Metode geolistrik memiliki dua tahanan jenis (resistivity) yaitu metode resistivity mapping dan metode resistivity sounding. Resistivity mapping memberikan informasi variasi tahanan jenis lapisan bawah permukaan arah horizontal. Resistivity sounding memberikan informasi variasi tahanan jenis lapisan bawah permukaan secara vertikal. Konfigurasi utuk mengukur geolistrik ada beberapa jenis yaitu, konfigurasi schlumberger, konfigurasi wenner, konfigurasi dipole-dipole, dan variasinya. Konfigurasi yang umum digunakan adalah konfigurasi schlumberger dan konfigurasi wenner (Bisri, 2003).

Data yang diperoleh selanjutnya digunakan sebagai input data untuk memperkirakan model lapisan jenis tahanan tanah bawah permukaan, diolah dengan bantuan software. IPI2WIN dan Res2Dinv adalah software yang sering digunakan untuk pemodelan, ada juga yang menggunakan software Interpex IX 1D-v.2 (Mohammaden dan Ehab, 2017).

Konfigurasi wenner memiliki ketelitian pembacaan tegangan pada elektroda MN lebih baik dengan angka yang relatif besar karena elektroda $\mathrm{MN}$ yang relatif dekat dengan elektroda AB. Susunan elektroda konfogurasi wenner ditunjukkan pada Gambar 1.

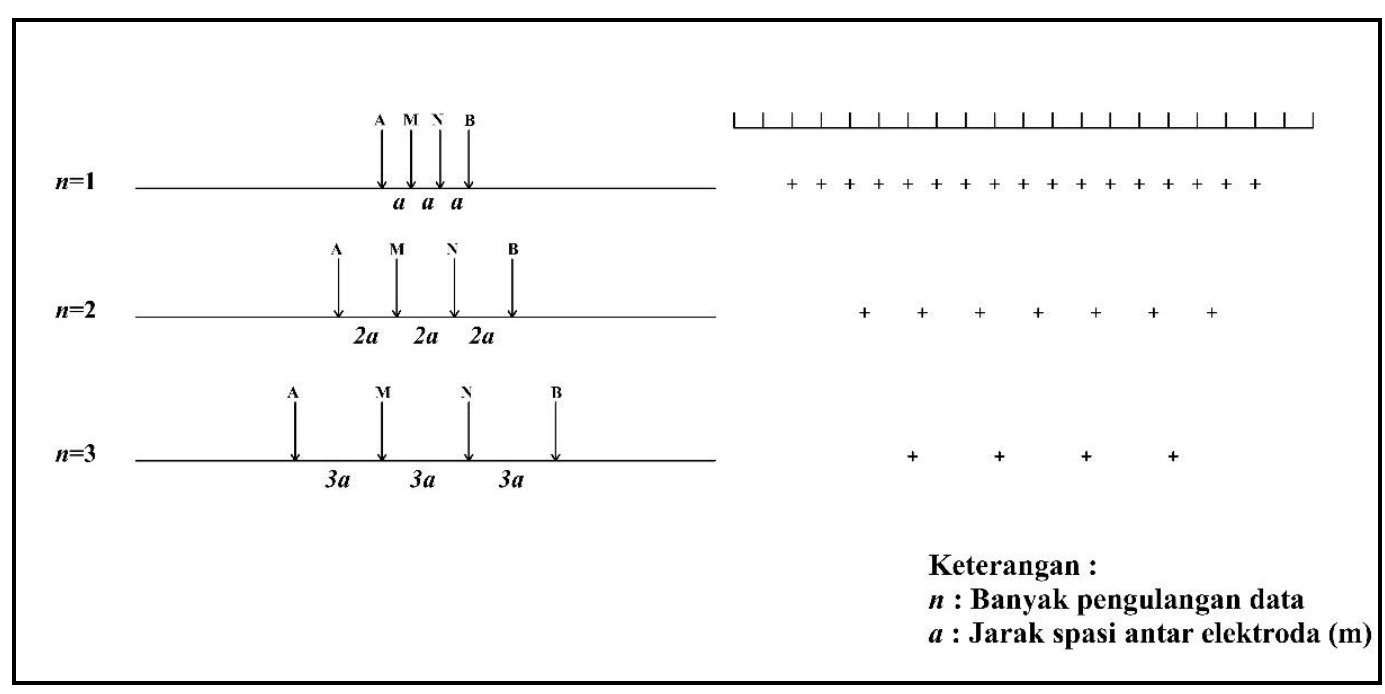

Gambar 1 Susunan elektroda konfigurasi wenner 
A dan $\mathrm{B}$ adalah elektroda arus. $\mathrm{M}$ dan $\mathrm{N}$ adalah elektroda potensial. $a$ merupakan jarak spasi antar elektroda dan $n$ adalah banyak pengulangan data.

\section{Metode Penelitian}

Lokasi penelitian berada di area Perumahan Grand Puri Bunga Nirwana, Jl. Tidar, Karangrejo, Sumbersari, Kabupaten Jember, Jawa Timur. Pendugaan air tanah menggunakan metode geolistrik resistivity mapping (horizontal). Konfigurasi yang diterapkan adalah konfigurasi wenner.

Lintasan pengukuran sepanjang 410 meter, ditunjukkan pada Gambar 2. Jarak spasi antar elektroda (a) yang digunakan adalah $5 \mathrm{~m}, 10 \mathrm{~m}$ dan $15 \mathrm{~m}$. Pengulangan data $(n)$ dilakukan 6 kali pada masing-masing pengukuran.

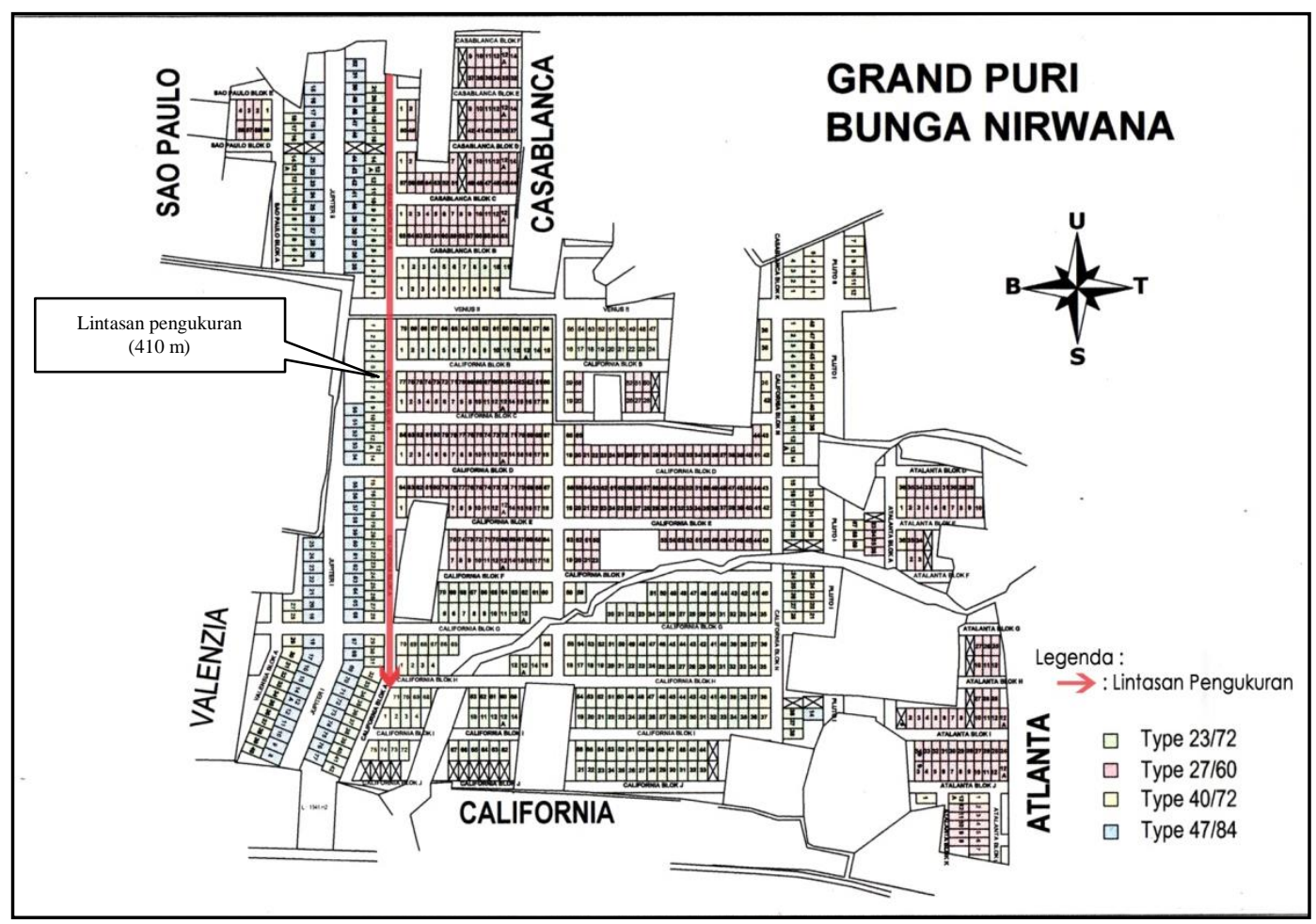

Gambar 2 Posisi lintasan pengukuran

Data yang diperoleh dihitung nilai tahanan jenis semu menggunakan persamaan :

$$
\rho_{a}=2 \pi a \frac{\Delta v}{I}
$$

Keterangan

$$
\begin{aligned}
\rho_{a} & =\text { tahanan jenis semu } \\
\Delta \mathrm{v} & =\text { beda potensial } \\
\mathrm{I} & =\text { arus } \\
\mathrm{a} & =\text { jarak spasi antar elektroda }
\end{aligned}
$$


Data tahanan jenis semu $\left(\rho_{a}\right)$ diinversi atau dimodelkan menggunakan bantuan software. Software yang digunakan untuk inversi model adalah Res2Dinv. Hasil inversi berupa nilai tahanan jenis yang sesungguhnya.

\section{Hasil dan Pembahasan}

Lokasi penelitian yang berada di Perumahan Grand Puri Bunga Nirwana, merupakan bekas daerah persawahan yang sedang tahap pembangunan untuk dijadikan daerah perumahan, terletak di Karangrejo, Sumbersai, Kabupaten Jember. Lokasi penelitian merupakan daerah ber-irigasi. Secara geologi, lokasi penelitian berada pada daerah tuff Argopuro kwarter endapan vulkanik muda, terdiri dari tufa, lahar breksi dan lava andesit sampai basal. Nilai kelulusannya tinggi hingga sedang.

Secara hidrogeologi, produktifitas akuifer lokasi penelitian tergolong akuifer sedang, dengan penyebaran luas. Akuifer lokasi penelitian merupakan akuifer dengan aliran melalui ruang antar butir, memiliki keterusan sedang sampai tinggi. Muka air tanah beragam, hingga kedalaman lebih dari 10 meter. Debit sumur umumnya kurang dari 5 liter/detik. Hal ini dapat ditunjukkan dengan gambar peta Hidrogeologi Kabupaten Jember pada Gambar 3.

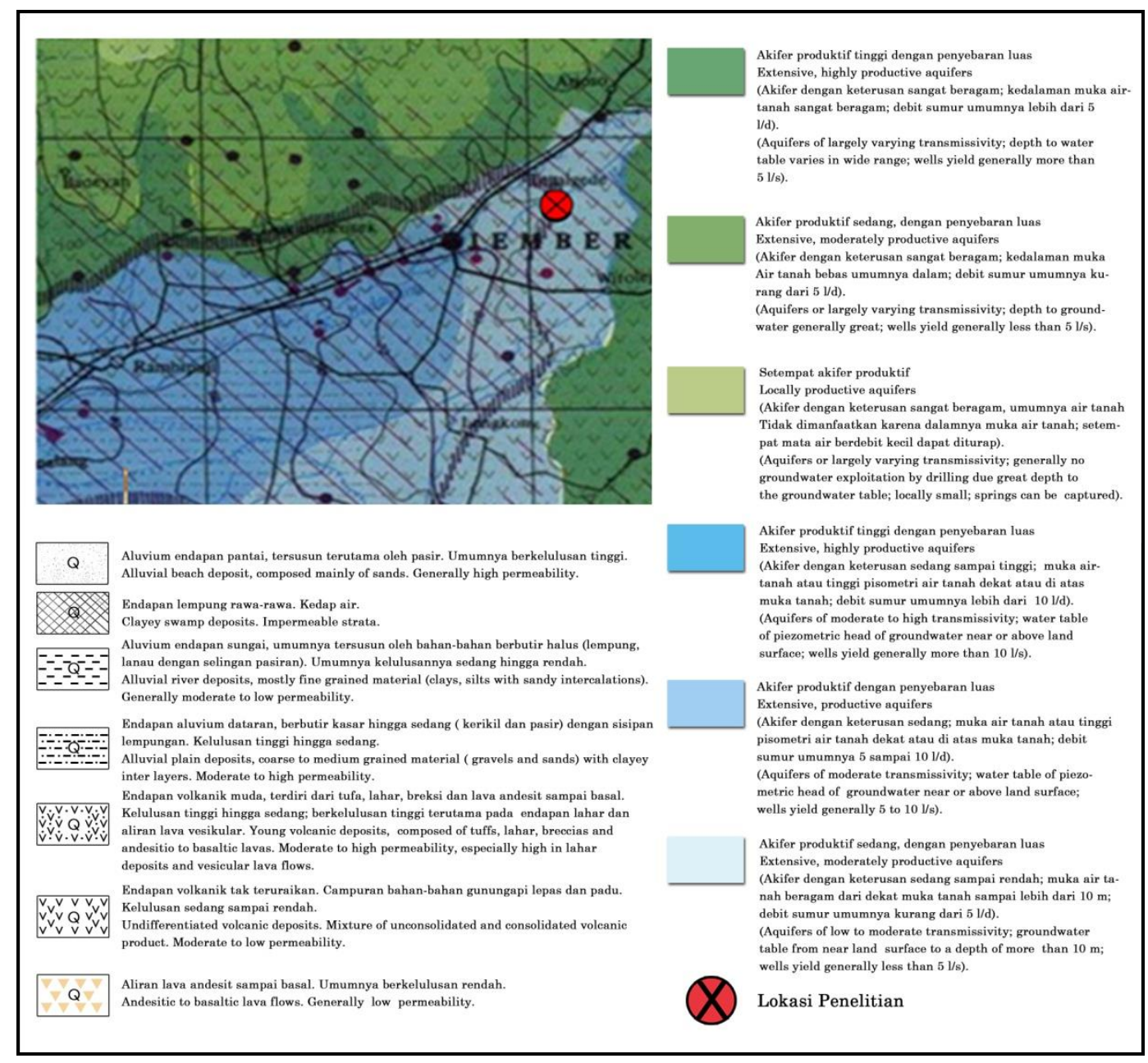

Gambar 3 Peta Hidrogeologi

Geolistrik Konfigurasi Wenner Untuk Pendugaan Air Tanah di Perumahan Grand Puri Bunga Nirwana Jember - Eri Kusworowati, Gusfan Halik, Wiwik Yunarni W 
Berdasarkan nilai tahanan jenis, data hidrogeologi, data geologi dan penelitian terdahulu dapat dipelajari profil dari lapisan bawah permukaan tanah.

Data olahan dari sofware berupa distribusi resistivitas bawah permukaan tanah termasuk akuifer yang diwakili oleh pencitraan warna berbeda-beda yang memberikan informasi mengenai gambaran struktur bawah permukaan tanah yang diwakili oleh nilai resistivitas semu. Citra warna tersebut selanjutnya digunakan untuk mengidentifikasi jenis batuan serta menduga keberadaan air tanah.

Hasil Pengukuran spasi elektroda 5 meter, 10 meter dan 15 meter menunjukkan lapisan akuifer yang cukup luas, berada pada rentang jarak lintasan antara 30 meter sampai 315 meter. Jika dilakukan pengeboran titik yang paling memungkinkan yaitu pada jarak lintasan 225 meter, diduga lapisan akuifer cukup tebal. Perbandingan hasil citra Res2Dinv antara spasi elektroda $5 \mathrm{~m}, 10 \mathrm{~m}$, dan $15 \mathrm{~m}$ ditunjukkan pada Gambar 4.

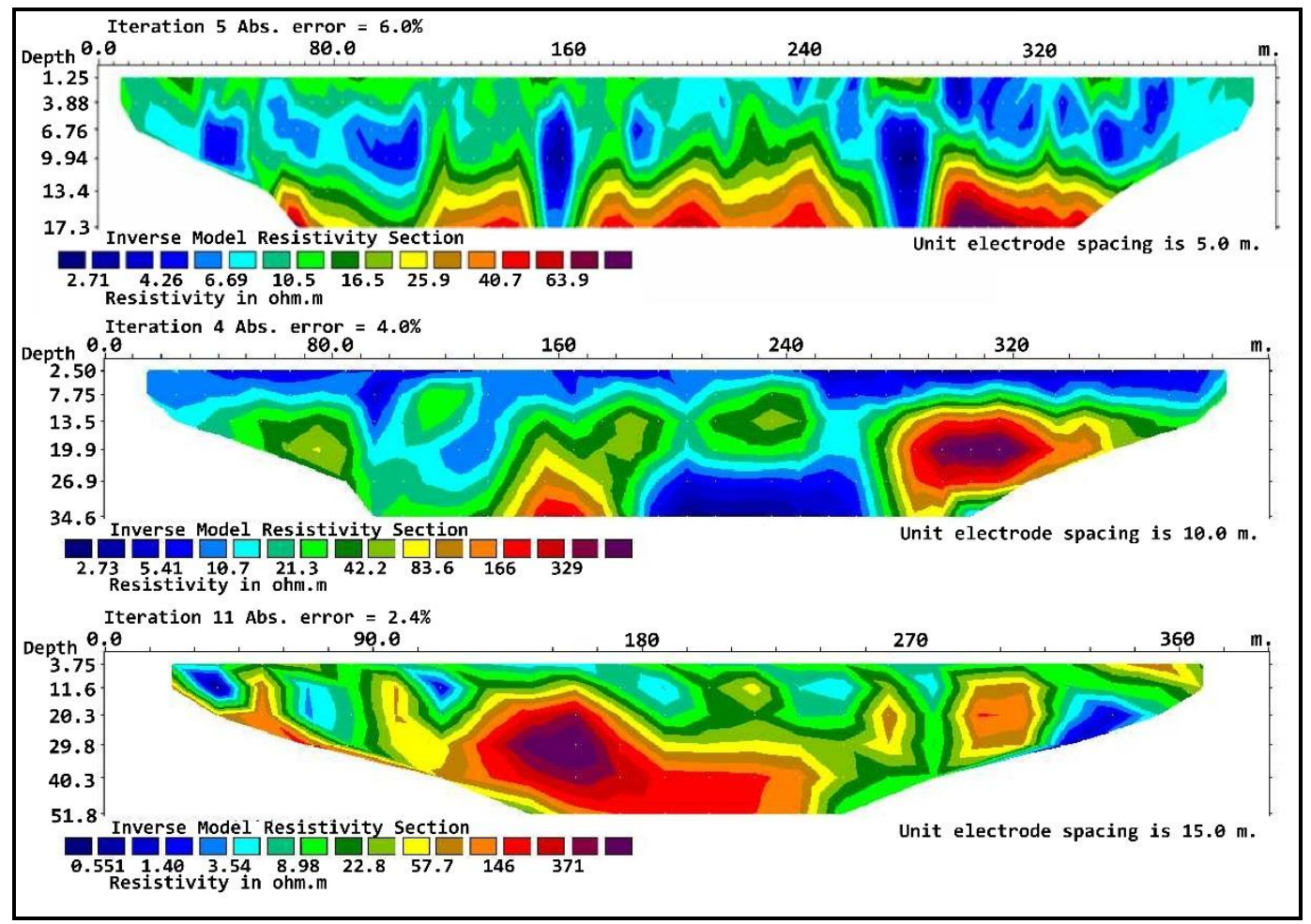

Gambar 4 Perbandingan citra Res2Dinv antara spasi elektroda 5m, 10, dan 15 m

Sumbu X (pada Gambar 4), menunjukkan kedalaman yang diperoleh, sedangkan sumbu $\mathrm{Y}$ menunjukkan panjang bentang lintasan yang digunakan dalam penelitian. Panjang lintasan pengukuruan yang digunakan adalah 410 meter. Kedalaman maksimum yang diperoleh adalah 51,8 meter.

Nilai resistivitas yang diperoleh antara $0,55 \Omega \mathrm{m}$ sampai dengan $371 \Omega \mathrm{m}$. Resistivity log vertikal kebawah dengan perbandingan kedalaman, nilai resistivitas semu tanah dan interpretasi data disajikan dalam Tabel 1- Tabel 3. 
Tabel 1 Interpretasi data pengukuran jarak spasi elektroda $5 \mathrm{~m}$

\begin{tabular}{ccccc}
\hline No & $\begin{array}{c}\text { Kedalaman } \\
(\mathbf{m})\end{array}$ & $\begin{array}{c}\text { Nilai Tahanan } \\
\text { Jenis }(\mathbf{\Omega m})\end{array}$ & Dugaan Lapisan & $\begin{array}{c}\text { Konfigurasi } \\
\text { Warna }\end{array}$ \\
\hline 1. & $0-11,8$ & $6,69-16,5$ & $\begin{array}{c}\text { Lapisan lempung dan } \\
\text { lempung pasiran }\end{array}$ & Biru 6 dan hijau \\
\hline 2. & $11,8-17,3$ & 25,9 & $\begin{array}{c}\text { Lapisan lempung, } \\
\text { lempung berpasir dan } \\
\text { tufa }\end{array}$ & $\begin{array}{c}\text { Kuning, coklat } \\
\text { dan oranye }\end{array}$ \\
\hline
\end{tabular}

Tabel 2 Interpretasi data pengukuran jarak spasi elektroda $10 \mathrm{~m}$

\begin{tabular}{ccccc}
\hline No & $\begin{array}{c}\text { Kedalaman } \\
(\mathbf{m})\end{array}$ & $\begin{array}{c}\text { Nilai Tahanan } \\
\text { Jenis }(\mathbf{\Omega} \mathbf{m})\end{array}$ & Dugaan Lapisan & $\begin{array}{c}\text { Konfigurasi } \\
\text { Warna }\end{array}$ \\
\hline 1. & $0-5,5$ & 10,7 & $\begin{array}{c}\text { Lapisan lempung dan } \\
\text { lempung pasiran }\end{array}$ & $\begin{array}{c}\text { Biru 5 dan biru } \\
6\end{array}$ \\
\hline 2. & $5,5-23,4$ & $21,3-42,2$ & $\begin{array}{c}\text { Lapisan lempung, } \\
\text { lempung berpasir dan } \\
\text { tufa }\end{array}$ & Hijau \\
\hline 3. & $23,4-34,6$ & $2,73-10,7$ & $\begin{array}{c}\text { Lapisanlempung } \\
\text { berpasir dan batu pasir }\end{array}$ & Biru \\
\hline
\end{tabular}

Tabel 3 Interpretasi data pengukuran jarak spasi elektroda $15 \mathrm{~m}$

\begin{tabular}{ccccc}
\hline No & $\begin{array}{c}\text { Kedalaman } \\
(\mathbf{m})\end{array}$ & $\begin{array}{c}\text { Nilai Tahanan } \\
\text { Jenis }(\mathbf{\Omega m})\end{array}$ & Dugaan Lapisan & $\begin{array}{c}\text { Konfigurasi } \\
\text { Warna }\end{array}$ \\
\hline 1. & $0-10,1$ & 8,98 & $\begin{array}{c}\text { Lapisan lempung dan } \\
\text { lempung pasiran }\end{array}$ & Hijau 1 \\
\hline 2. & $10,1-28,7$ & 22,8 & $\begin{array}{c}\text { Lapisan lempung, } \\
\text { lempung berpasir dan } \\
\text { tufa }\end{array}$ & $\begin{array}{c}\text { Hijau 2, hijau 3 } \\
\text { dan hijau 4 }\end{array}$ \\
\hline 3. & $28,7-37,2$ & 57,7 & $\begin{array}{c}\text { Lapisanlempung } \\
\text { berpasir dan batu pasir }\end{array}$ & $\begin{array}{c}\text { Kuning dan } \\
\text { coklat }\end{array}$ \\
\hline 4. & $37,2-51,8$ & 146 & $\begin{array}{c}\text { Lapisan batu pasir,pasir } \\
\text { dan kerikil jenuh air }\end{array}$ & Oranye \\
\hline
\end{tabular}

Berdasarkan tabel interpretasi data pada Tabel 1 - Tabel 3, pada kedalaman $0 \mathrm{~m}-10 \mathrm{~m}$ belum ditemukan air tanah, dugaan lapisan berupa lempung dan lempung pasiran. Pada kedalaman10-23 m terdapat air tanah, diduga merupakan air sumur dangkal, lapisan penyusun berupa lanau, lempung pasiran dan tufa.

Pada kedalaman 23-38 m diduga lapisan lempung pasiran dan batu pasir. Pada kedalaman 38-51,8 m diduga sebagai lapisan pembawa air (akuifer), penyusun lapisan akuifer berupa batu pasir, pasir dan kerikil jenuh air.

\section{Kesimpulan dan Saran}

\subsection{Kesimpulan}

Berdasarkan hasil penelitian dapat disimpulkan bahwa secara geologi daerah penelitian memiliki komposisi litologi batuan endapan vulkanik muda. Batuan penyusunnya berupa lempung, lempung pasiran, lanau, tufa, batu pasir, pasir dan 
kerikil. Secara hidrogeologi, akuifer tergolong produktif sedang dengan penyebaran luas. Akuifer mengalir melalui ruang antar butir. Potensi akuifer diprediksi kurang dari 5 liter/detik. Lapisan akuifer berada pada kedalaman 38$51,8 \mathrm{~m}$, akuisisi data pada koordinat $8^{\circ} 10,29^{\prime} 40^{\prime \prime} \mathrm{S}$ dan $113^{\circ} 44^{\prime} 7,20^{\prime}$ ' $\mathrm{E}$.

\subsection{Saran}

Berdasarkan hasil penelitian dapat disarankan bahwa untuk mendapatkan informasi distribusi nilai resistivitas yang lebih dalam pada arah vertikal, diperlukan penyelidikan geolistrik medote resistivitas sounding.

\section{Daftar Kepustakaan}

Bakri, H. dkk. 2015. Pendugaan Air Tanah dengan Metode Geolistrik Tahanan Jenis di Desa Tellumpanua Kec.Tanete Rilau Kab. Barru Sulawesi Selatan. Jurnal Geomine. 3: 165-169.

Bisri, M. 2003. Aliran Air Tanah. Malang: Fakultas Teknik Universitas Brawijaya.

Halik, G., Widodo, J. 2008. Pendugaan Potensi Ait Tanah dengan Metode Geolistrik Konfigurasi Schlumberger Di Kampus Tegal Boto Universitas Jember. Media Teknik Sipil. 109-114.

Mohammaden, Ehab. 2017. Application of Electrical Resistivity for Groundwater Exploration in Wadi Rahaba, Shalateen, Egypt. NRIAG Journal of Astronomy and Geophysics. 6: 201-209.

Priyono, P., Rizal N.S.. 2013. Kajian Potensi Air Tanah dengan Metode Geolistrik sebagai Antisipasi Kelangkaan Air Bersih Wilayah Perkotaan. Jurnal Elevasi. 4(18): 35-42.

Wijaya. A.S.. (2015). Aplikasi Metode Geolistrik Resistivitas Konfigurasi Wenner untuk Menentukan Struktur Tanah di Halaman Belakang SCC ITS Surabaya. Jurnal Fisika Indonesia .19(55): 1-5. 